\title{
The Position of Psychological Expert Evidence under the Malaysian Evidence Act 1950
}

\section{Ramalinggam Rajamanickam}

\author{
Faculty of Law, The National University of Malaysia, 43600 Bangi, Selangor Darul Ehsan, Malaysia \\ Email: rama@ukm.my
}

Anita Abdul Rahim

Faculty of Law, The National University of Malaysia, 43600 Bangi, Selangor Darul Ehsan, Malaysia Email: aar@ukm.my

\section{Doi:10.5901/mjss.2014.v5n14p128}

\section{Abstract}

While courts depend on expert opinions in reaching sound judgments, the role of the expert witness in legal proceedings is associated with a litany of problems. Perhaps most prevalent is the question of under what circumstances should testimony be admitted as expert opinion. There is no concept of the 'free appreciation of evidence'. It will not necessarily suffice, in other words, to show that a given item of evidence is relevant to some disputed issue in the case. Relevance is clearly important, because no court will waste time listening to evidence which is manifestly irrelevant to any fact of the issues in the case; but regard must also be had to the questions of admissibility. Thus, this writing focuses on the relevancy of psychologists' evidence under Section 45 of the Evidence Act 1950. This writing also addresses the issue of admissibility of psychologists' evidence and the courts' attitude towards the reception of expert evidence from psychologists. To date, the Malaysian courts are using strict approach with regards to the issue of permitting the psychologists to give expert testimony in any cases. This strict approach should be relaxed in order to allow the psychological evidence is given to help the judges in deciding any issue related to psychology.

Keywords: admissibility; expert opinion; psychologist; relevancy

\section{Introduction}

Expert witnesses play a large and increasingly important role in the trial of actions in Malaysia. The majority of all civil and criminal cases currently litigated involve expert evidence of some sort. The law allows most witnesses to testify only about facts, but expert witnesses are uniquely permitted to give evidence of their opinions as well. The role of expert witness is different from that of any other witness in a criminal trial as an expert is the only type of witness who can give opinion evidence. Opinion evidence is evidence in the form of an inference or a conclusion, rather than a statement of the facts from which the inference or conclusion has been drawn; or evidence of facts based on conjecture or belief, rather than personal knowledge. "Opinion" is a slippery term that can include both inferences and other non-factual evidence (Reutlinger, 1996, p. 181).

With the increasing complexity of cases, particularly those that require the resolution of scientific or technical questions, the expert witness has become critical to the success of litigation. Expert can provide a bridge between the particular facts of a case and patterns of fact that can be observed and understood only through much wider study (Jack Matson, Suha Daou \& Jeffrey Soper, 2004, p. 7).

The involvement of psychologists as expert witnesses in legal proceedings has increased steadily since psychologists first entered the courtroom about a century ago (Gudjonsson, 1991). Psychologists may become involved as expert witnesses in both criminal and civil proceedings and they may be instructed by the defence, prosecution or the court. Psychologists may be called to provide an expert opinion at various stages of the legal process, for example, in criminal cases; psychologists may give expert evidence during the trial, before sentencing and at the appeals stage. Psychological evidence, however, has generally been treated as a special case and has not won such easy acceptance (Mackay and Colman, 1995, p. 261). 


\section{The Legal Definition of 'Expert'}

The Evidence Law recognizes two categories of witnesses. Lay witnesses, also called percipient of fact witnesses, are called to testify because they have seen, heard, or done something relevant to the facts and circumstances of the case. The testimony of such witnesses contributes directly to establishing the factual events (Jack Matson, Suha Daou \& Jeffrey Soper, 2004, p. 7). The second category is the expert witness. An expert witness is a person who, by reasons of education or special training, possesses knowledge of a particular subject that may be beyond the understanding of the average person. Experts are not always required. They are hired only if their expertise is necessary to present technical and/or complex facts, or to provide expert opinions based upon their knowledge, experience, and qualifications (Jack Matson, Suha Daou \& Jeffrey Soper, 2004, p. 7). In addition to that, expert witness also can be defined as a witness who, because of specialized knowledge, skill, training, experience, or education, is particularly qualified to give an opinion or draw an inference about a matter within that area of expertise (Reutlinger, 1996, p. 188).

Before a court will admit evidence of an expert it must be satisfied that the witness has the appropriate expertise. Generally, an expert witness can be defined as a person possessing certain specialized knowledge, training, education, skill and/or experience that goes beyond the knowledge of ordinary members of the general public. The expert witness is used to explain and provide opinions about particularly complex issues that are beyond the general knowledge of most people. Richard Saferstein states that expert witness may be defined as "an individual whom the court determines to possess knowledge relevant to the trial that is not expected of the average layperson" (Saferstein, 2007, p. 18). Expert witness also has been defined as "an individual who is required to appear in court in order to give factual information and opinion based on fact, from within his or her area of expertise" (Andrew \& Julie, 2008, p. 432).

An expert is a person who, by reason of education or special training, possesses knowledge of a particular subject area in greater depth than does the public at large (JackMatson, Suha Daou \& Jeffrey Soper, 2004, p. 6). According to Section 4 of New Zealand Evidence Act 2006, expert means "a person who has specialised knowledge or skill based on training, study, or experience." While, expert evidence means "the evidence of an expert based on the specialised knowledge or skill of that expert and includes evidence given in the form of an opinion" (Section 4 of New Zealand Evidence Act 2006).

An Expert, according to Lord Russell CJ in the case of The Queen v Silverlock [1894] 2 QB 766 at p.771 is:

"someone who is skilled and has adequate knowledge in an area of expertise. Qualifications of an expert may have been acquired through study, training or experience."

Whereas, in the case of PP $v$ Lee Ee Teong [1953] MLJ 244, the court held that:

"A person who is skilled or knowledgeable on certain matters by reason of his experience and exposure may be an expert.'

An expert's opinion is a reasoned conclusion drawn from specialised knowledge based on facts which the expert has observed, assumed, or been instructed to assume (Kumar, 2011, p. 427). It is necessary to demonstrate to the court that the "expert" possesses specialize, relevant knowledge ordinarily not expected of the average layperson. Such knowledge can be acquired through any combination of education and practical experience, and augmented through a study of books and journals in the field. Writing, research, and active membership in pertinent professional organizations are expected of most experts if they are to be considered current in the field (James Osterburg \& Richard Ward, 2010, p. 42). Once in the witness box, the expert must be limited to giving evidence within the scope of his or her expertise. Thus, a psychologist is not qualified to diagnose mental illness as it is not the expertise of a psychologist.

\section{Role of Psychologists as Experts}

Expert witnesses, because of their experience and training, are able to contribute useful opinions based on the observations of others as well as themselves. However, the witnesses' opinions are admitted only if and to the extent they are likely to aid the trier of fact in reaching its ultimate conclusions on the evidence (Reutlinger, 1996, p. 183). Unlike ordinary "lay" witnesses, the expert witness is called not to testify with respect to the factual background of an action but rather to provide an opinion with respect to those facts which will help the judge, jury or tribunal reach its conclusion. The ability of an expert witness to provide evidence in connection with a factual situation with which they had no connection is thus a major exception to the hearsay rule, which generally provides that indirect evidence may not be led to support the truth of the matter asserted. (O'Melia, 1991, p. 1). The job of the 'expert witness' is not simply to articulate their client's 
position; it is to assist the decision maker (a court, tribunal or other similar body) with the information about the specialist area which is necessary before a decision can be made (Sutherland, 2009, p. 1).

The task of an expert witness can be described as "[f]ormulating a scientific opinion which will assist the trier of fact (i.e. judge or jury) in rendering a final decision" (Van Dorsten, 2002, p. 2). In the case of Ong Chan Tow v R [1963] MLJ 160, Singapore High Court through Winslow J held that:

"Experts should not be asked to give conclusions on matters which eminently matters for the court to decide."

Similarly, in Chin Sen Wah v PP [1958] 24 MLJ 154, High Court of Malaya decided that:

"The ultimate decision on any issue is with court."

However, it must be remembered that if the court cannot reach a proper conclusion or decision without the assistance of the psychologists, then the court must call the psychologists to give expert evidence on that matter. This is the well established principle in Malaysian courts. In Syed Abu Bakar bin Ahmad v PP [1984] 2 MLJ 12 at p.23-24, Abdul Hamid FJ held that:

\section{"It is settled principle that while it is true that a Judge who sits alone is entitled to weigh all the evidence, to put his own magnifying glass to determine the probabilities so to speak and form his own opinion or judgment, it would be erroneous for him to form a conclusion on a matter which could only be properly concluded with the aid for expert evidence."}

Thus, by applying the above principles, the role of psychologist as an expert is to assist the court to form a proper conclusion through their expertise. The psychologists should not give any conclusion on any matters which eminently matters for the court to decide. The psychologists may only give opinion on the matters within their area of expertise i.e. psychology.

The psychologists are permitted to give expert testimony in court when the issue to be tried is beyond the common knowledge or experience of the judge. If the disputed issues are within the common knowledge or experience of the judges, the court will disallow the psychologists to give evidence on that matter. In $R$ v Coles (1995) 1 Cr App R 157 the trial judge refused to admit expert psychological testimony in answer to a reckless arson charge on the ground that the 15-year-old defendant's mental capacity, though lower than average, did not disclose any evidence of abnormality. In upholding this decision, the Court of Appeal ruled that the evidence in question related solely to characteristics of the defendant that could be evaluated competently by a jury through reference to the facts without the assistance of expert evidence, because adolescents of varying stages of maturity and brightness were all within the common experience of jurors.

\section{The Relevancy of Psychologists' Evidence under the Malaysian Evidence Act 1950}

In Malaysia, the legislation pertaining to evidence is Evidence Act 1950. Thus, in order to know the position of psychology expert evidence in Malaysia, the provision of Evidence Act 1950 must be construed. The evidence of psychology expert must be relevant before the court can admit it. Relevancy is a concept that runs through the Evidence Act 1950. The significance of relevancy is apparent. Whatever is not provided for in the Act is irrelevant and therefore inadmissible. Consequently, only evidence declared relevant by the Act can be considered as judicial evidence. Meaning that, in order for the court to admit the psychology expert evidence in Malaysia, it must be relevant under any one of the provisions in the Evidence Act 1950.

There is no specific provision with regards to psychological expert evidence in the Evidence Act 1950. But, the general provision relating to relevancy of expert evidence is covered under Section 45 of the Evidence Act 1950. Section 45 states that:

1) When the court has to form an opinion upon a point of foreign law or of science or art, or as to identity or genuineness of handwriting or finger impressions, the opinions upon that point of persons specially skilled in that foreign law, science or art, or in questions as to identity or genuineness of handwriting or finger impressions, are relevant facts.

2) Such persons are called experts.

Based on the provision of Section 45, there are few categories of expert accepted by the law i.e. experts in foreign law, experts in science or art, experts in identity or genuineness of handwriting or finger impressions. It is submitted here that there is no specific category for psychology in the above provision, thus what is the legal position for psychological 
expert?

Psychology has been defined as diverse discipline, grounded in science, but with nearly boundless applications in everyday life. Some psychologists do basic research, developing theories and testing them through carefully honed research methods involving observation, experimentation and analysis. Other psychologists apply the discipline's scientific knowledge to help people, organisations and communities function better. (American Psychological Association, 2013) Psychology is also defined as science that deals with mental processes and behaviour. It is a scientific study of all forms of human and animal behaviour, sometimes concerned with the methods through which behaviour can be modified. (Farlex, The Free Dictionary http://www.thefreedictionary.com/psychology). Therefore basically, psychology can be considered as a scientific study of the human mind and its functions, especially those effecting behaviour in a given context. In other words, it deals with the mental characteristics or attitude of a person.

Looking at the definition of psychology, it can be construed that the terms 'science or art' as provided under section 45 of the Malaysian Evidence Act 1950 may also encompass the field of psychology as part of it. This can be further supported by looking at the definition of science or art. According to Article 49 Stephen's Digest of the Law of Evidence, the words "science or art" include all subjects on which a course of special study or experience is necessary to the formation of an opinion,' and amongst others the examination of handwriting. Meanwhile, based on Field's Expert Evidence, the term 'science' or 'art' must be interpreted widely. Moreover, in the case of Chandrasekaran \& Ors v PP [1971] 1 MLJ 153, the court held that:

"The expression 'science or art' is elastic enough to be given a liberal interpretation."

Thus, it is submitted that the evidence of psychologists is relevant under the category of 'science or art' under the scope of expert opinion.

\section{Legal issues Arising from the Admissibility of Psychologists' Evidence under the Malaysian Evidence Law}

In this country, the only criterion to admit the expert evidence is relevance. As long as the evidence is relevant to the issue, it is admissible. This is the general principle under the Malaysian Evidence Act 1950. Thus, based on this principle, the evidence of a psychologist may be admitted as long as it is relevant to the facts in issue. In practice, however, the courts do not simply allow the expert evidence of psychologists to be tendered in any case even though it has passed the test of relevancy.

According to the provision of Section 45 of the Evidence Act 1950, the court may seek the assistance of the expert when the issue of the case involves the questions of 'science or art.' As explained above, the psychology is a discipline which falls under the category of 'science or art' and therefore, it has passed the test of relevancy. However, this is not as simple as that. Although the evidence of psychologists is relevant according to the Section 45 but the court always has the discretionary power to decide whether or not to call a psychologist in any cases.

In Malaysia, there is another important question to be considered before the psychologists may be permitted to testify as the experts. The psychologists will only be called to testify on any issue if the court feels it is necessary to do so. Although expert opinion, especially on medical and scientific matters, has been admitted as evidence in court increasingly often since the nineteenth century, psychological or psychiatric evidence has always been treated as a special case and has not been welcomed so readily by the courts. (Mackay and Colman, 1991, p. 88).

The Malaysian courts are bound with the principle of necessity laid down by the case of $R \vee$ Turner [1975] QB 834. In $R \vee$ Turner, the defendant had killed his girlfriend with a hammer after she told him with a grin that she had been sleeping with two other men and that the child that she was carrying was not his. He pleaded provocation, claiming that he had been overwhelmed with blind rage and had hit her with the hammer without realising what he was doing. Although he showed no signs of any mental disorder, the defence wished to introduce psychiatric evidence to show that he had enjoyed a deep emotional relationship with the deceased, that he was likely to have experienced an explosive outburst of blind rage after her confession to him, and that after the crime his behaviour showed profound grief for what he had done, which was consistent with his defence of provocation. But after examining a psychiatric report outlining the evidence that the expert witness intended to give, the trial judge ruled the evidence inadmissible on the ground that it dealt with matters of 'common knowledge and experience' within the experience of the jury. Lawton LJ justified the Court of Appeal decision as follows in $R \vee$ Turner at $\mathrm{p}$. 841:

"If on the proven facts a judge or jury can form their own conclusions without help, then the opinion of an expert is unnecessary. In such a case if it is given dressed up in scientific jargon it may make judgment more difficult. The fact 
that an expert witness has impressive qualifications does not by that fact alone make his opinion on matters of human nature and behaviour within the limits of normality any more helpful than that of the jurors themselves; but there is a danger that they may think it does."

Based on this case, the evidence from a psychologist will only be allowed to be given on any issue if the evidence is necessary for the court. Meaning that, when the court is unable to decide any issue without the help of the psychologists, their evidence are necessary for that issue and therefore, the court must call the psychologist. In most situations involving psychological issues, the Malaysian courts are reluctant to call psychologists as experts as they feel that it is unnecessary due to the fact that psychology is within their common knowledge and experience.

For more than 35 years, the decision in $R$. v. Turner had the effect of excluding psychological evidence from numerous cases. The effect of the Turner rule has been to exclude evidence on the assumption that the psychological functions and phenomena are matters of "common knowledge and experience." According to the court, a judge can understand the psychological issues without the help of experts, although the underlying assumption about the transparency of non-clinical psychological processes is certainly open to challenge (Mackay and Colman, 1991).

Similarly, in $R$ v. Abbey [1982] 2 S.C.R. 24 at p. 42, Mr. Justice Dickson (as he then was) of the Supreme Court of Canada commented on the role which experts play in the trial process as follows:

\begin{abstract}
"Witnesses testify as to facts. The judge or jury draws inferences from facts. With respect to matters calling for special knowledge, an expert in the field may draw inferences and state his opinion. An expert's function is precisely this: to provide the judge and jury with the ready-made inference which the judge and jury, due to the technical nature of the facts, are unable to formulate. An expert's opinion is admissible to furnish the court with scientific information, which is likely to be outside the experience and knowledge of a judge or jury. If on the proven facts a judge or jury can form their own conclusions without help, then the opinion of the expert is unnecessary."
\end{abstract}

The Turner rule continues to dominate the question of the admissibility of psychological testimony in Malaysian courts. Accordingly, if the behaviours of an accused are not claimed to be abnormal, the judges must use their own knowledge and experience to decide the issue in question. The Turner rule has been used to exclude expert psychological and psychiatric evidence in innumerable criminal cases since 1975 (Mackay and Colman, 1991, 1996). Following this leading case, the courts have been comparatively indulgent in their readiness to admit expert psychological and psychiatric testimony in cases involving pleas of diminished responsibility, though not where defendants have voluntarily consumed alcohol or dangerous drugs, but they have been reluctant, for a time at least, to admit such testimony in cases in which defendants pleaded provocation and those involving other issues of criminal responsibility or mens rea.

It is submitted that the Turner rule restricts the admissibility of psychological evidence to the supposedly 'abnormal' behaviours. Meaning that, all 'normal' forms of behaviour are within the common knowledge and experience of a judge. Few years before Roskill LJ in the case of $R \vee$ Chard (1971) $56 \mathrm{Cr}$ App R 268, had commented at pp. 270-271:

"Where the matters in issue go outside [the jury's] experience and they are invited to deal with someone supposedly abnormal, for example, supposedly suffering from insanity or diminished responsibility, then plainly in such a case they are entitled to the benefit of expert evidence. But where, as in the present case, they are dealing with someone who by concession was on the medical evidence entirely normal, it seems to this court abundantly plain, on first principles of the admissibility of expert evidence, that it is not permissible to call a witness, whatever his personal experience, merely to tell the jury how he thinks an accused man's mind assumedly a normal mind operated at the time of an alleged crime.

According to Roskill LJ, the normal, non-disordered behaviour is fully transparent and therefore not in need of explanation or clarification by experts i.e. the psychologists in our case.

Here, the fundamental question to be answered is whether the Turner rule is the best practice in deciding the issue related to psychology. Should the Malaysian courts allow the psychologists only on the basis of necessity? Does the attitude of Malaysian judges in rejecting the psychologists to give expert evidence on the grounds that the issues are within their common knowledge or experience must be changed?

Based on the nature of psychology as a field which requires a special study, experience or training to become an expert in that area, it is recommended that the Malaysian courts should relax their attitude towards accepting the evidence of psychologists in many issues. A key premise of this argument, which was already well established in the common law in 1975, was that all psychological processes except those involving some form of mental abnormality are part and parcel of the common knowledge and experience of a jury. The courts always feel that the psychological issues are within the common knowledge and experience of the judge and therefore, they do not require any specific experts on 
that matter.

However, the courts must always remember that the discipline of psychology is extremely broad in its attempt to understand individual and social functioning from a psychological perspective. The court may get the help of the psychologists to provide expert evidence about a wide variety of psychological issues. It would be more reasonable to extend the range of psychological expert testimony to include forms of behaviour that poorly understood by ordinary people.

Every major branch of psychology contains vast quantities of information that are both "complex and not known by the public at large." Without serious and sustained study of psychology, no member of the public at large could come anywhere near passing a psychology examination at first-year university level (Mackay and Colman, 1995, p. 264).

The relax approach in terms of psychological evidence can be seen clearly in the case $R$. v. Sally Lorraine Emery (and Another) (1993) 14 Cr.App.R.(S.) 394. In this case, Sally Emery was the 19-year-old unmarried mother of a child who died before she was a year old of injuries resulting from prolonged physical abuse. In January 1992, a jury in the Peterborough Crown Court acquitted Emery of occasioning actual bodily harm but convicted her of failing to protect her child from its father. She claimed in her defence that she had been under duress, that the father had routinely abused both the child and herself, and that fear had prevented her from protecting the child. Her counsel applied to call two expert witnesses-a psychologist with many years' experience working with abused women and a psychiatrist with specialist knowledge of responses to serious trauma-to testify that exposure to continued abuse had reduced her to a condition of dependent helplessness, which explained her failure to protect her child. The prosecution contested the application on the ground that the proposed evidence dealt not with any recognised mental disorder but with matters within the common knowledge and experience of the jury. The trial judge ruled the evidence admissible, and the experts duly testified in Emery's defence. The jury nonetheless found her guilty of failing to protect her child, and she was sentenced to four years' detention in a young offender institution, but she appealed against this sentence and it was reduced to 30 months by the Court of Appeal in November 1992. In allowing the expert evidence, the trial judge, Michael Astill J at p. 397 states that:

\begin{abstract}
"There is potential expert evidence to the effect that if she is right, her will could have been crushed. That would afford her a good defence ... Therefore, without further explanation or understanding, the jury's lack of understanding might lead to a guilty verdict, whereas if they were to consider the expert evidence which seeks to explain her conduct, they [might] find her not guilty. It follows from that that in my judgment the effects of abuse of the scale and persistence she describes might well not be within the capacity of a jury to understand unassisted by expert evidence."
\end{abstract}

In case of Emery, Lord Taylor $\mathrm{CJ}$ in the Court of Appeal had fully endorsed the decision of trial judge and its justification. Lord Taylor commented at p.397 that the condition of dependent helplessness that was the subject of the proposed expert testimony "is complex and it is not known by the public at large. Accordingly we are quite satisfied that it was appropriate for the learned judge to decide that this evidence should be allowed"

The Court of Appeal's decision in Emery did not eliminate the essence of the rule in Turner, that the expert evidence dealing with matters within the "common knowledge and experience" of the jurors remains inadmissible, but the application of the rule appeared to have been relaxed so as to permit expert testimony relating to a condition which, although not a mental disorder, "is complex and ... is not known by the public at large."

The effect of the Emery judgment therefore appears to open the door to psychological evidence in a far wider range of areas than has hitherto been the case (Colman and Mackay, 1995 p.264)

\title{
6. Concluding Remarks
}

The use of expert psychological evidence in court can heavily influence the outcome of a case and impact directly or indirectly on the individuals involved and society more broadly. To date, the Malaysian courts are reluctant to call the psychologists to give expert testimony in psychological matters especially non-clinical psychology. The Turner rule has been used to exclude psychological evidence on many issues in Malaysia. In England, the Turner rule still excludes testimony dealing with matters that are deemed by the judge to lie within the "common knowledge and experience" of a jury but the barriers against expert psychological evidence were lifted by recent legal decisions in $R$. v. Sally Lorraine Emery (and Another). The Turner rule is no longer interpreted to exclude all psychological and psychiatric evidence relating to non-clinical psychological phenomena. This is a more flexible approach in terms of psychological evidence.

The Malaysian courts should use this approach in deciding whether to allow a psychologist to give expert evidence in any case. With this relax attitude, many psychologists will enter the courtroom to assist the judges in forming a proper 
conclusion. Human behaviours are very complex and complicated. Not all human will react in the same way under the same situation. Thus, the judges cannot regard the issue of human behaviours as within their common knowledge or experience.

\section{References}

A. M. Colman and R. D. Mackay, Psychological Evidence in Court: Legal Developments in England and the United States, Psychology, Crime \& Law (1995) Vol. 1. pp 261-268

Andrew Jackson, R.W. and Julie Jackson, M. (2008). Forensic Science, Second Edition, Pearson Education Limited, England

Jack Matson, V. Suha Daou, F. and Jeffrey Soper, G. (2004). Effective Expert Witnessing, Fourth Edition, CRC Press, United States of America

Gudjonsson, G. (1991). The trial of psychiatry: Insanity in the twentieth century. In K. Herbst \& J. Gunn (Eds.), Mentally disordered offender. Oxford: Butterworth Heinemann.

James Osterburg, W. and Richard Ward, H. (2010). Criminal investigation: A Method for Reconstructing the Past, Sixth Edition, LexisNexis

Kumar, M. (2011). Admissibility of Expert Evidence: Proving the Basis for an Expert's Opinion, Sydney Law Review [VOL 33:427]

Mackay, RD. and Colman, A.M. (1991), 'Excluding Expert Evidence: A Tale of Ordinary Folk and Common Experience,' Criminal Law Review, pp. 800-10.

Mackay, RD. and Colman, A.M. (1996), 'Equivocal Rulings on Expert Psychological and Psychiatric Evidence: Turning A Muddle into A Nonsense,' Criminal Law Review, pp. 88-95.

O'Melia, J. (November 1991). The Expert Witness, Miller Thomson, Canada

Reutlinger, M. (1996). Evidence: Essential Terms and Concepts, Aspen Law and Business, United States of America

Saferstein, R. (2007). Criminalistics: An Introduction to Forensic Science, Ninth Edition, Pearson Education International, New Jersey

Sutherland, R. (20 April 2009). Expert Evidence: The Role, Duties and Responsibilities of the Expert Witness in Litigation, this article is based on a presentation which was first delivered at an Expert Witness Training Seminar hosted by Terra Firma Chambers

Van Dorsten, B. (2002). Forensic Psychology. In B. van Dorsten (Ed.), Forensic Psychology: From classroom to courtroom (pp. 1-16). New York: Kluwer Academic/Plenum Publishers. 